\title{
Molecular Epidemiology of Cystic Echinococcosis: Genotypic Characterization in Humans and Different Livestock
}

\author{
Epidemiología Molecular de la Equinococosis Quística: Caracterización \\ Genotípica en Humanos y Diferentes Animales
}

\author{
Carlos Manterola ${ }^{*, * * * * * * *} \&$ Tamara Otzen ${ }^{* * * * * * * *}$
}

MANTEROLA, C. \& OTZEN, T. Molecular epidemiology of cystic echinococcosis: Genotypic characterization in humans and different livestock. Int. J. Morphol., 34(4) :1472-1481, 2016.

SUMMARY: Echinococcus Granulosus (EG) is the major cause of cystic echinococcosis in humans and livestock in the world. In Chile is a zoonosis of great importance. The most frequently affected geographic areas are the Regions of Aysén, Los Rios, Los Lagos, Coquimbo and the Araucanía. Hence, it was discovered that in endemic areas of hydatidosis there could be several strains and genotypes of EG. In addition, there is evidence that some strains and genotypes are more infectious for human beings than others. This interesting phenomenon of the biology of EG has been studied using molecular biology techniques based on polymerase chain reaction (PCR) and DNA sequence analysis, which has made it possible to characterize the cestode species complex called EG sensu lato (s 1) as being comprised of EG sensu stricto (s.s.) (Genotypes G1-G3), E. equinus (G4), E. ortleppi (G5) and E. canadensis (G6-G10), which present an important phenotypic variation detectable in characteristics of the biological cycle, specificity of the intermediate host, pattern of development, pathogenicity, antigenicity, transmission dynamics and, consequently, in the measures needed to control the disease. The aim of this manuscript is to describe the different genotypes of EG described in humans and different livestock host reported in the literature.

KEY WORDS: Echinococcus granulosus; Genotypes; cytochrome c oxidase subunit I; PCR-RAPD.

\section{INTRODUCTION}

Echinococcus granulosus (EG) is the major cause of cystic echinococcosis in humans and livestock in the world. In Chile is a zoonosis of great importance, as it constitutes a public health problem with strong socio-economic repercussions. The prevalence is 5 per 100.000 inhabitants nationally, and in the Region of the Araucanía it is 48 per 100.000 inhabitants (Fig. 1), particularly in rural areas where the population still incorrectly disposes of biological waste from animals slaughtered clandestinely (Serra et al., 1995; Manterola et al., 1997).

The high incidence and prevalence in these areas causes serious public health problems, including, it must be noted, the appearance of advanced stages of the disease with unusual forms of presentation and various types of complications of the lesions (Manterola et al., 2003a; Manterola et al., 2003b; Manterola et al., 2004a; Manterola \& Otzen 2017), which in turn increases the risks of morbidity and mortality (Manterola et al., 2004b) with the resulting rise in health costs.

In a study of the economic impact of human and animal echinococcosis in Chile, it was confirmed that i) in 2012, 767 patients were treated surgically for hydatidosis, ii) the annual costs derived from surgical treatment alone were estimated at USD 2.46 million, iii) when adding secondary costs due to sick leaves and loss of productivity, these costs increased to USD 3.13 million, and iv) considering human and animal costs, the annual economic burden of the disease was estimated at USD 14.35 million. The most frequently affected geographic areas are the Regions of Aysén, Los Rios, Los Lagos, Coquimbo and the Araucanía (Venegas et al., 2014).

Therefore, this situation suggests a need to propose solutions that can be based on at least 4 possible perspectives:

* Department of Surgery, Universidad de La Frontera, Temuco, Chile.

** Center for Morphological and Surgical Studies (CEMyQ), Universidad de La Frontera, Temuco, Chile.

**** Center for Biomedical Research, Universidad Autónoma, Chile.

***** Universidad de Tarapacá, Arica, Chile.

Partially funded by project DID-UFRO DI16-0119 of Universidad de La Frontera. 


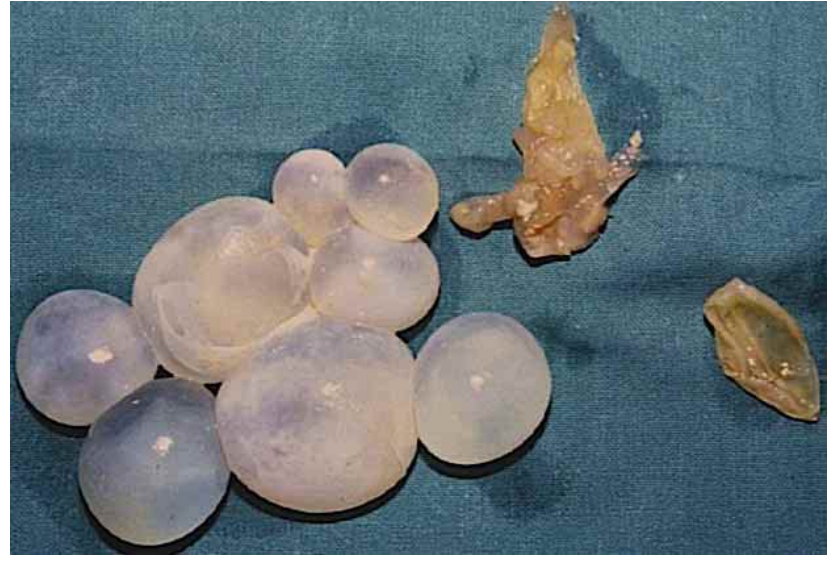

Fig. 1. Daughter's vesicles of a hydatid cyst of the liver in a human host.

education of the population (particularly those most susceptible to being infected), early diagnosis (especially in endemic areas), identification of risk factors (measure designed to recognize promptly those patients at greatest risk of disease-related morbidity and mortality), and the creation of a vaccine.

Hence, it was discovered that in endemic areas of hydatidosis there could be several strains and genotypes of EG (McManus \& Smith, 1986; Bowles \& McManus, 1993a), a fact that can impact various aspects of the epidemiology, pathology and control of the disease (Thompson \& Lymbery, 1998). In addition, there is evidence that some strains and genotypes are more infectious for human beings than others (Eckert \& Thompson, 1997). This interesting phenomenon of the biology of EG has been studied using molecular biology techniques based on polymerase chain reaction (PCR) and DNA sequence analysis, which has made it possible to characterize the cestode species complex called EG sensu lato (s l) as being comprised of EG sensu stricto (s.s.) (Genotypes G1-G3), E. equinus (G4), E. ortleppi (G5) and E. canadensis (G6-G10) (McManus \& Rishi, 1989; Bowles et al., 1992; Bowles et al., 1993a; Bowles \& McManus, 1993b; Bowles et al., 1994; Siles-Lucas et al., 1994; McManus et al., 1995; Scott et al., 1997), which present an important phenotypic variation detectable in characteristics of the biological cycle (Fig. 2), specificity of the intermediate host, pattern of development, pathogenicity, antigenicity, transmission dynamics and, consequently, in the measures needed to control the disease.

A great objective of these types of studies would be to develop vaccines against some specific genotypes. In this respect, some studies describe the difficulty of this initiative, given that the antigen of the protection vaccine (EG95), developed for the G1 genotype, is immunologically different in the G6 genotype; therefore, greater evidence is needed to

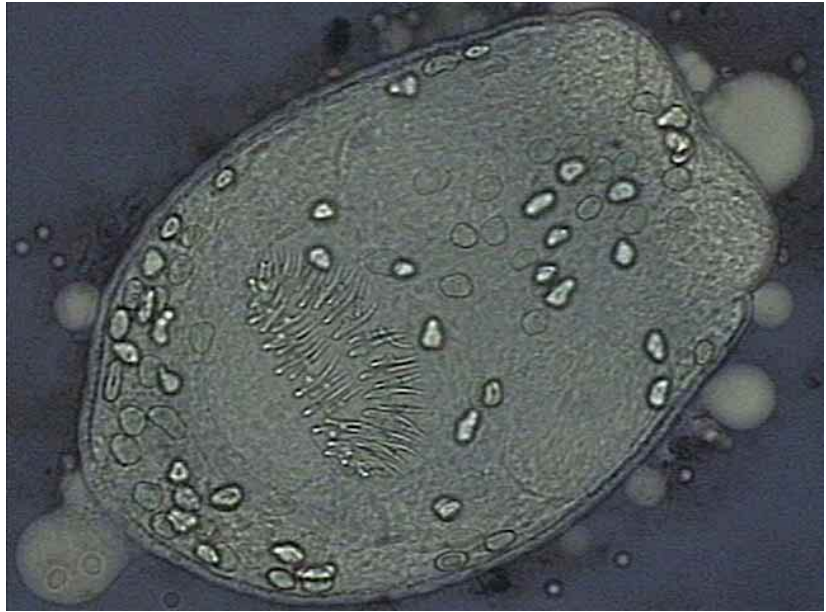

Fig. 2. Protoscolex obtained from hydatid sand of a human hydatid cyst. its intact membrane, calcareous corpuscles and chain hooks rostral appreciated.

determine whether the EG95 vaccine would be effective against the G6 or G7 genotypes, or if it would be necessary and possible to develop specific vaccines for each genotype (Alvarez Rojas et al., 2014). The sequence of the full length of the cytochrome c oxidase subunit I (COI) (1609 bp) gene was analyzed in $37 \mathrm{EG}$ isolates from different hosts and geographic regions in Australia, obtaining 7 haplotypes of EG s.s. not previously described, along with 5 haplotypes reported in other parts of the world, including the haplotype EG01, which is present in all the endemic regions. Such evidence points to further studies being required in the area (Alvarez Rojas et al., 2016).

\section{THEORETICAL FOUNDATIONS}

EG is one of the smallest tapeworms in the Taeniidae family. This organism demonstrates a great variation in terms of specificity of the host, epidemiology, morphology, developmental biology, physiology, biochemistry and genetics (Thompson \& Lymbery). Subspecific variants or strains have been identified, and a review of the taxonomy of the genus Echinococcus (Thompson et al., 1995; Thompson, 2002) has been proposed. These subspecific variants are around 10 genotypes distinct from the parasite (G1 to G10) (Bowles et al., 1992; Bowles et al., 1994; Bowles et al., 1993; Scott et al.; Lavikainen et al., 2003), although the validity of the $\mathrm{G} 9$ genotype has been questioned because it could correspond to the G7 (Snábel et al., 2000).

Several techniques have been applied to the direct study of the genetic variability of EG. Some working groups have focused their analysis on the regions of mitochondrial cytochrome regions of $\mathrm{COI}$ and $\mathrm{NADH}$ dehydrogenase 1 (ND1) of the parasite as genetic markers (Bowles et al., 1993; 
Bowles et al., 1994; Bowles et al., 1995; Zhang et al., 1998a; Snábel et al.) based on the sequencing of the mitochondrial DNA and highlighting its importance in the differentiation and discrimination of organisms from the same family, as in the case of Echinococcus strains, which seem to be evolutionary units of high homogeneity (Bowles \& McManus, 1993a; Bowles et al., 1993b; Bowles et al., 1992).

Previous studies into the identification and characterization of genotypes of EG have revealed the existence of nine genotypes, which have been linked to different animals, such as sheep, pigs, horses, camels, cattle, goats, etc. (Cuesta-Bandera et al., 1988; Siles-Lucas et al., 1993; Siles-Lucas et al., 1996a; Siles-Lucas et al., 1996b; Ponce-Gordo \& Cuesta-Bandera, 1997a; Ponce-Gordo \& Cuesta-Bandera, 1997b; Ponce-Gordo \& Cuesta-Bandera, 1998). One of the criteria used in those studies was the band diagram analysis of random amplified polymorphic DNA (RAPD) (Olivier et al., 1999). This method has proven to be fast and reliable, and has advantages over other techniques (larval morphology, in vitro development, isoenzyme standards and SDS-PAGE proteins); for example, RAPD can be used on infertile cysts because it requires small amounts of parasitic tissue, while it can also be applied to specimens that are fresh, frozen or fixed in alcohol. Nevertheless, the RAPD method has some drawbacks: it is very sensitive to changes in the reaction conditions (Olivier et al.), and it has low reproducibility and specificity due to the use of short primers (Ellsworth et al., 1993; Micheli et al., 1994; Valentini et al., 1996; Ponce-Gordo \& Cuesta-Bandera, 1997b; PonceGordo \& Cuesta-Bandera, 1998; Olivier et al.). Therefore, some groups have recommended the use of RAPD together with a PCR-restriction fragment length polymorphism (RFLP)-based analysis (PCR-RFLP) or DNA sequencing to obtain definitive results (Scott $e t a l$.). Preliminary results using these analytical methods were obtained by González et al. (2002), in the validation of an alternative method to discriminate EG genotypes in Spain, where, according to their results, there are only three (G1, G4 and G7). This method has an adequate internal and external validity, which makes it interesting to reproduce in other centers.

A PCR, followed by sequencing, on the mitochondrial genes COI and Nad1 is the gold standard test at laboratory level for addressing both the Taenia sp. determination as well the detection of Echinococcus sp. with subsequent species determination. The polymorphisms in these genes are so useful for typing (Roelfsema et al., 2016).

In this light, EG is considered a tapeworm parasite of great medical and veterinary importance, as it is responsible for cystic echinococcosis, a condition that is among the most serious parasitic diseases in human beings, representing 1 of the 17 neglected diseases prioritized by the Word Health Organization (Laurimaa et al., 2015).

\section{AVAILABLE EVIDENCE}

Bowles et al. (1994) of the Molecular Parasitology Unit of the Institute of Medical Research in Brisbane, Australia, studied the genetic characteristics of the "northern strain" of EG by applying a PCR analysis of the ITS1 nuclear region of the rDNA, finding that this variety presented ambiguities at position 18, which make it similar in structure to the G1 genotype (common in the domestic sheep), G2 (common in Tasmanian sheep) and G3 (common in buffalo). On the other hand, when they applied the mitochondrial ND1 sequence protocol, they observed a similarity with the G6 genotype (common in the camel) and the G7 (usual in pigs). The reactions observed support the notion that the "northern strain" of EG is a special genotype designated G8 (Bowles et al., 1994).

Siles-Lucas et al. (1994), of the Department of Parasitology at the University of Madrid, Spain, used different molecular biology methods to examine isolates of EG from Switzerland and Spain, finding that the samples exhibited characteristic band patterns that confirmed that they belonged to horse and donkey isolates from Switzerland and Spain, cattle from Switzerland, sheep of Spain, and pigs from Switzerland and Spain, and goats from Spain (SilesLucas et al.).

Scott et al. (1997), of the Molecular Parasitology Unit of the Institute of Medical Research in Brisbane, Australia, analyzed EG isolates from pigs and humans in Poland, obtained using a fine needle puncture. The samples were processed by nuclear (ITS1) and mitochondrial sequencing (ND1) and then by application of restriction enzymes, observing that the Polish patients were not infected with the G1 genotype (associated with sheep and human infection), but rather a genotype similar to G7 (characteristic of pigs) was isolated in these patients, which represented a different genotype of EG that was called G9 (Scott et al.).

Zhang et al. (1998a), of the Molecular Parasitology Unit at the Australian Center for Tropical Diseases in Brisbane, Australia, examined 28 EG isolates from the Xinjiang Uygur region in China. The samples were obtained from sheep, cattle, camels and operated human hydatid cysts. After applying a DNA sequencing protocol to the mitochondrial cytochrome $\mathrm{c}$ oxidase subunit 1 and NADH dehydrogenase genes, they determined the existence of G6 (from camels) and G1 (from sheep and humans). The latter genotype was isolated exclusively in samples from the northern area of Xinjiang Uygur (Zhang et al.). 
Zhang et al. (1998b), of the Molecular Parasitology Unit at the Australian Center for Tropical Diseases in Brisbane, Australia, studied 16 Echinococcus isolates from Iranian operated patients and from domestic animals in the geographic area of Tehran (including sheep, cattle, goats and camels). The samples were treated using a protocol to analyze the DNA nucleotides and to predict the sequence variations of the amino acids in the mitochondrial cytochrome c oxidase subunit 1 and NADH dehydrogenase genes. After applying a PCR and restriction enzymes, they found two different G6 (from dogs and camels) and G1 (from sheep, domestic animals and humans) genotypes (Zhang et al.).

Snabel. et al., of the Institute of Parasitology at the Slovak Academy of Sciences in Kosice, Slovakia, determined the genotype of pig protoscolices in the Slovak territory, applying a mitochondrial (ND1) and nuclear (ITS1) sequence protocol, finding a high affinity of the samples with the G7 genotype (characterized by a double precipitation band pattern), which was the first report of the existence of the G7 genotype in Slovakia (Snabel et al.).

González et al., of the National Microbiology Center in Madrid, Spain, verified 53 EG isolates in the central region of Spain (endemic for Echinococcosis). They extracted the complete genomic DNA, then amplified the DNA and this was automatically sequenced with a fluorescence base. The digested DNA samples were subjected to electrophoresis and hybridizations were done at $68{ }^{\circ} \mathrm{C}$. The DNA sequences were analyzed by the program Primer Select Lasergenen, and then amplified with PCR. The protocols made it possible to distinguish 2 genetic groups within the Spanish pig isolates: the G1 (sheep strain) and G7 (pig strain) genotypes. This observation can have a significant impact on public health care in Spain, since these pigs could infect human beings as has been reported in Eastern and Central Europe (González et al.).

Le et al. (2002), of the Unit of Molecular Parasitology at the International Center for Tropical Diseases in Brisbane, Australia, studied the complete mitochondrial genome of two genotypes of EG, G1 (sheep-dog strain) and G4 (horsedog), which were compared with genomes from E. multilocularis and Hymenolepis diminuta, which had similar structures, lengths and composition (Le et al.).

Lavikainen et al. of the Department of Bacteriology and Immunology of the Haartman Institute at the University of Helsinki, Finland, analyzed 5 EG isolates from rodents in northeastern Finland, analyzing the DNA sequences of the mitochondrial cytochrome c oxidase subunit 1 and the NADH dehydrogenase, and the internal transcribed spacer ITS- 1 of the ribosomal fragment. They observed that the analyzed samples were similar to the G6 genotype; however, and according to the phylogenetic analysis, the isolates were also associated with the G7, G5 and G8 genotypes; as a result, it was considered that they were dealing with a new genotype, which they called "Fennoscandian cervid strain" and assigned it the G10 genotype (Lavikainen et al.).

Guarnera et al. (2004) of the Department of Parasitology at the National Institute of Infectious Diseases in Buenos Aires, Argentina, examined 41 patients with hepatic, pulmonary, splenic and multiorgan hydatidosis from the provinces of Neuquén and Tucuman, applying a protocol for sequencing mitochondrial COI. They found the G1 genotype (associated with common sheep) in 19 patients; the G2 genotype (related to sheep in Tasmania) in 6 patients, the G5 genotype (linked to cattle) in 1 patient, and the G6 genotype (associated with camels) in 15 patients. This finding is peculiar because the camel is not a common animal in Argentina (Guarnera et al.).

Daniel Mwambete et al. (2004), from the Department of Parasitology at the Complutense University of Madrid, Spain, verified cyst samples obtained from sheep, goats, cows, pigs and horses destroyed at local slaughterhouses in central Spain, to which specimens from human hydatid cysts and wild boars hunted in the central area of Spain were added. They worked with 248 isolates from hepatic and pulmonary cysts with a similar degree of fertility. They extracted the genomic DNA of the protoscolices or germinal membranes. They later applied PCR amplification reactions, finding 3 different genotypes: G1 (highly fertile and preference for sheep), G4 (no host preference and located exclusively in the liver of the infested animal), and G7 (preference for pigs, in which greater fertility was observed in hepatic than in pulmonary cysts) (Daniel-Mwambete et al., 2004).

Mrad et al. (2005), of the Laboratory of Parasitology and Mycology at the Faculty of Pharmacy in Monastir, Tunisia, studied 372 cysts from 50 humans, 166 cattle, 153 sheep and 3 camels (all from Tunisia). After applying an analysis of the ITS sequence with PCR-RFLP, it was found that all the human, sheep and cattle samples corresponded to the G1 genotype and that the camel samples were related to G6 (Mrad et al.).

Boufana et al. (2008), of the Biomedical Sciences Research Institute at the University of Salford, UK, studied the performance of three PCR tests for the identification of the G1 genotype of EG in sheep, from canine tissue and fecal samples. The "Dinkel" and "Stefanic' ${ }^{\prime \prime}$ primers were the most sensitive in the DNA detection of EG in dog feces and autopsies (73.7 \% and $100 \%$, respectively). The "Abbasi" primers only detected $52.6 \%$ of EG in the infected 
dogs, but were more specific for the species, since the reaction crossed with E. shiquicus occurred in $90.9 \%$ of the tissue samples and in $75 \%$ of the fecal samples. The "Stefanic $"$ primers were the least specific for EG $(27.3 \%$ in tissues and $25 \%$ in feces). The "Dinkel" primers also showed crossed reactivity between species $(63.6 \%$ in tissues and $100 \%$ in feces); however, they were more specific for the G1 strain of EG in sheep (Boufana et al.).

Manterola et al. (2008), of the Surgery Department at the Universidad de La Frontera, studied hydatid fluid and sand samples from patients operated on for hepatic and pulmonary hydatidosis in the regional hospital in Temuco, Chile, between 2004 and 2005. Two PCR systems were used: PCR Eg 9 (Fig. 3) and PCR Eg 16. The RSA 1 enzyme was used for RFLP.

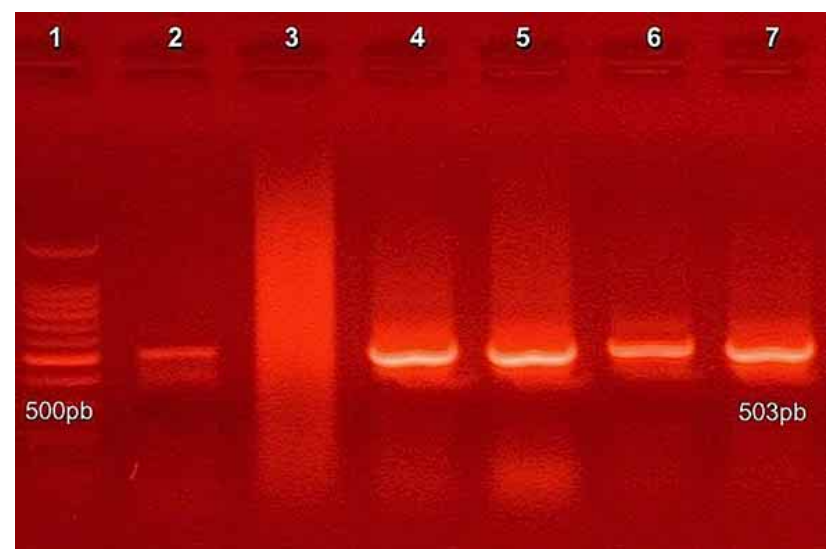

Fig. 3. EG9 PCR for DNA detection of Echinococcus granulosus in samples of human hydatid cyst. Agarose gel stained with $2 \%$ ethidium bromide, shown in lane 1 marker $100 \mathrm{bp}$. In lanes 2, 4, 5, 6 and 7 positive samples. In lane 3 , sample not amplified.

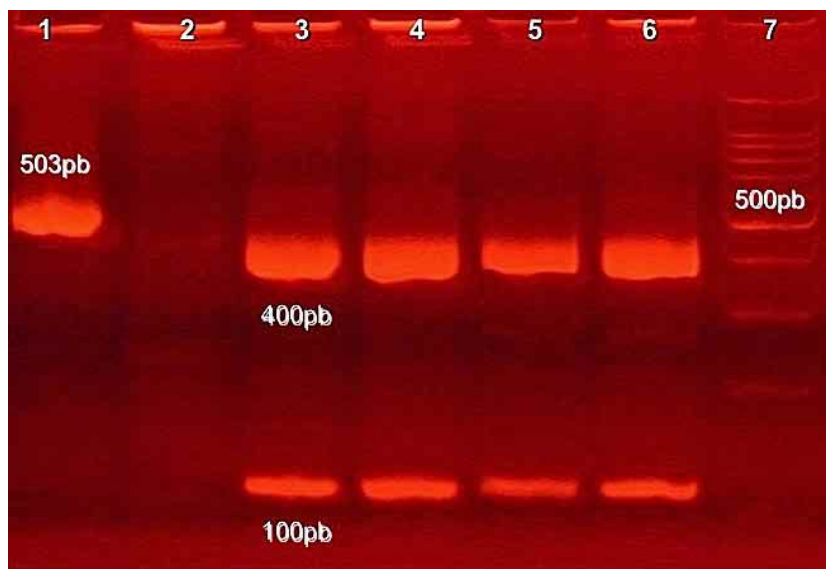

Fig. 4. EG9 PCR products digested with RsaI enzyme for DNA detection of Echinococcus granulosus in samples of human hydatid cyst. Polyacrylamide gel stained with $2 \%$ ethidium bromide, shown in lane 1 a RSA not cut. In lane 2 no amplified product. In lines 3, 4,5 and 6 positive samples for enzymatic digestion. In line 7 marker $100 \mathrm{bp}$.
The genotype was confirmed using the sequence of a fragment of 366 base pairs from a mitochondrial gene (COI). The DNA of protoscolices from 24 samples (4 from pulmonary cysts and 20 from hepatic cysts) was analyzed. The fragment of 366 bp was amplified in 20 of the 24 samples $(83.3 \%)$. The enzymatic digestion (Fig. 4), revealed the presence of 3 possible genotypes: in 20 of 21 samples $(95.2 \%)$, a restriction was observed that corresponds to $\mathrm{G} 1$ or G7; in the remaining samples, it was determined that it could be G4 or G7. The final sequencing confirmed the presence of the G1 genotype in 19 samples and the G6 genotype for the remainder (G4 or G7 according to PCR-RFLP) (Manterola et al.).

Santivañez et al. (2008), of the Department of Microbiology at the Peruvian University Cayetano Heredia, Peru, conducted a molecular study by PCR using DNA from 21 hydatid cysts to determine the strains responsible for human infection in Peru. Amplification was applied using mitochondrial COI to 20 of 21 samples, revealing that all but one $(95 \%)$ belonged to the G1 strain in common sheep. The remaining samples belonged to the camel strain (G6) (Santivañez et al.).

Casulli et al. (2010), of the Department of Infectious and Parasitic at the Istituto Superiore di Sanità in Rome, Italy, performed a molecular analysis to identify EG genotypes causing human echinococcosis in the district of Turkana, Kenya (1993-1994). 71 cyst samples were taken using PAIR (puncture, aspiration, injection, reaspiration) procedures. The DNA of 59 isolates was amplified. Of these, 49 isolates $(83 \%)$ were identified as $\mathrm{G} 1$ and $10(17 \%)$ as G6 (Casulli et al.).

Soriano et al. (2010), of the Chair of Microbiology and Parasitology at the Universidad Nacional del Comahue (Neuquén, Argentina), studied the fertility, viability and molecular epidemiology of the hydatid cysts obtained from local goats $(n=23)$, pigs $(n=18)$ and sheep $(n=16)$ to identify possible reservoirs of E. canadensis (G6). Isolates from infected dogs (adult worms from 10 dogs) were also analyzed. They identified a total of 67 strains by DNA sequencing of mitochondrial cytochrome $\mathrm{C}$ oxidase subunit 1 . They detected E. canadensis (G6) in 21 of 23 goat samples; E. canadensis (G7) in all the pig samples; EG senso estricto (G3) in 1 sheep and G1 in 15 sheep, 2 goats and 9 dog samples. This was the first study to describe the existence of EG senso estricto (G3) in South America and to verify that goats act as a reservoir of E. canadensis (G6) in Neuquén (Soriano et al.).

Nakao et al. (2010), of the Department of Parasitology at Asahikawa Medical College in Hokkaido, Japan, investigated the genetic polymorphisms of Echinococcus spp. in the eastern part of the Tibetan plateau and the Region of 
Xinjiang, applying a DNA sequencing analysis to the mitochondrial COI and nuclear elongation factor- 1 alpha. Thus, they obtained 68 strains of EG senso estricto (S. S.) in Xinjiang. Additionally, 113 strains of EG s. s., 49 strains of E. multilocularis and 34 strains of E. shiquicus on the Tibetan plateau were isolated. Molecular identification using mitochondrial and nuclear markers was identical, suggesting a low frequency of introgressive hybridization (Nakao et al.).

Aaty et al. (2012), of the Faculty of Medicine at Ain Shams University, Abasia Square, Cairo, Egypt, analyzed isolates from 47 camels, 6 pigs and 31 humans (21 hepatic, 5 pulmonary and 5 multiorgan). The G6 genotype was verified in all the animal isolates (100\%) and in 30 of 31 $(96.8 \%)$ of the human isolates. This was done using the specific Hot-Start PCR followed by mitochondrial DNA $12 \mathrm{~S}$ rRNA sequencing. The nucleotide sequence of the Egyptian G6 strain revealed $100 \%$ homology with an Argentinian reference strain with $99 \%$ homology with the G6 strain from Kenya. It was concluded that G6 is the predominant genotype in Egypt (Aaty et al.).

Andresiuk et al. (2013), from the Laboratory of Parasitic Zoonoses, FCEyN, UNMdP, Mar del Plata, Buenos Aires, Argentina, genetically characterized 42 isolates from cattle and 34 from sheep from the pampas in the province of Buenos Aires, Argentina. Using sequencing with mitochondrial COI and nad 1 genes, they verified that the predominant genotype was G1, with the exception of two identified as G2 and G5 (Andresiuk et al.).

Boufana et al. (2013) of the Cestode Zoonoses Research Group, University of Salford, UK, applied three PCR techniques based on the amplification of a fragment of the NADH dehydrogenase subunit 1 (ND1) in samples of EG G1, E. shiquicus and E. multilocularis obtained from parasitic tissue and fecal samples from dogs. A specificity of $100 \%$ was verified when DNA derived from parasitic tissue was used, except for E. shiquicus primers, which barely detected DNA. The sensitivity of the three DNA detection techniques was between 2 and 10 gp. For the PCR-negative fecal samples, precipitation with ethanol was used to eliminate false negatives and increase sensitivity, as could be seen when the detection increased from $0 \%$ to $89 \%$ in the case of E. shiquicus coproDNA using samples from fox with an autopsy positive for echinococcosis (Boufana et al.).

Konyaev et al. (2013), of the Institute of Animal Ecology in Novosibirsk, Russia, studied a total of 75 samples of Echinococcus in European Russia and the Altai region between 2010 and 2012, finding the G6, G8 and G10 genotypes. In addition, 4 genotypes of E. multilocularis were identified (Konyaev et al.).
Espinoza et al. (2014), of the Agribusiness Faculty of the Universidad de La Frontera, analyzed samples of human and bovine hydatid cysts, for which they used segments of COI and NADH dehydrogenase (ND1). The phylogenetic analysis showed that most of the analyzed samples were G1; however, a sample of the cysts from a bovine lung $(\mathrm{Q} 21)$, with the $\mathrm{COI}$ marker, was grouped in a node together with a sample belonging to the G3 genotype. In the phylogenetic tree obtained with the ND1 marker, this sample was grouped with the sequences of the G3, G2, and G4 genotypes. These results were significant as G2 and G3 had not been described previously in Chile (Espinoza et al.).

Boufana et al. (2014) of the Ecosystems and Environment Research Centre at the University of Salford, UK and other related centers, analyzed 174 Echinococcus isolates from human beings and ungulate intermediate hosts and adult tapeworms from dogs and jackals. They identified EG sensu stricto, from all the host species examined, E. canadensis (G6) in a camel, and for the first time the fertile cysts of EG (s.s.) and E. equinus in equids (donkeys) and EG (s.s.) in wild boars and goats. A considerable genetic variation for the EG COI (S. S.) sequences was observed. The pairwise fixation index (FST) for COI EG (s.s.) sequences in donkeys was high and statistically significant compared to the populations of EG in other intermediate hosts. A single haplotype (EqTu01) was identified by the nucleotide sequences of equine Echinococcus (Boufana $e t$ al.).

Alvarez Rojas et al. (2014), of the Faculty of Veterinary Sciences at the University of Melbourne, Australia and other related centers, suggested that the allocation of samples to $\mathrm{G}$ numbers is becoming increasingly difficult, as there is greater variability than previously known in the G1-3 (EG senso estricto), E. equino (G4), E. ortleppi (G5) and E. canadensis (G6-7, G-8, G10) genotypes. The G1 genotype is responsible for most of the human cystic echinococcosis ( $88.4 \%$ worldwide). The G6 and G7 genotypes (closely related) cause a significant number of human infections (11.1\%). G5, G8 and G10, however, have been identified in human samples, but with less frequency. Cases of human infection by G4 have not been described. Finally, they proposed that the biological differences between species and genotypes have the potential to affect the transmission dynamics of the parasite (Alvarez Rojas et al.).

Babazadeh et al. (2015), from the Department of Clinical Sciences at the School of Veterinary Medicine at the University of Shiraz, Iran, analyzed DNA samples from protoscolices extracted from hepatic hydatid cysts in a twoyear-old male water buffalo, slaughtered in the province of Khuzestan. A comparative analysis was made of COI 
mitochondrial gene sequences with which phylogenetic molecular analyses were conducted. The existence of a new microvariant of the G3 genotype was found in Iran, with genetic differences from the G3 reference sequence (M84663). The difference is a transition mutation from adenine to guanine at position 214 (A214G), which is a substitution of threonine (ACT) for alanine (GCT). This contributes to knowledge of the heterogeneity and distribution of the G3 genotype for EG in the world (Babazadeh et al.).

Laurimaa et al., from the Zoology Department of the Institute of Ecology and Earth Sciences at the University of Tartu, Estonia, studied fecal sample from 181 stray dogs in an urban area of Estonia in 2012-13, reporting positivity for EG in $2.2 \%$ of the cases, with sequencing for the G1 genotype (positivity was not verified for E. multilocularis).

Boufana et al. (2015) of the Ecosystems and Environment Research Centre at the University of Salford, UK and other related centers, studied hydatid cysts isolated in horses, cysts recovered from mammals in captivity, and coproDNA from hunting dogs and farm dogs, identifying $\mathrm{E}$. equino from the horse samples, EG (S. S.) in cattle and sheep samples and from farm dog feces. A variation in the haplotypes of EG (S. S.) was detected in the COI sequences (Boufana et al.).

Cucher et al. (2016), Research Institute for Medical Microbiology and Parasitology at the University of Buenos Aires, Argentina and other related centers, performed a systematic review of the literature, in which they found information geared toward South America in Argentina, Brazil, Chile, Peru and Uruguay, reporting sequencing data from 1534 cases of EG s. s. (G1). Similarly, the analysis of the cases all over the world showed that $72.9 \%$ of the cases in humans are caused by EG s. s. (G1), and $12.2 \%$ and $9.6 \%$ by E. canadensis G6 and G7, respectively (Cucher et al.).

Spotin et al. (2016) of the Immunology Research Center, Tabriz University of Medical Sciences, Tabriz, Iran and other related centers, sequenced 79 isolates from different host species covering human, dog, camel, goat, sheep and cattle as of various geographical sub-populations of Iran (Northwestern, Northern, and Southeastern), and 36 sequences of other geographical populations (Western, Southeastern and Central Iran). The confirmed isolates were grouped as G1 genotype ( $n=92)$, G6 genotype $(n=14), G 3$ genotype $(n=8)$ and $\mathrm{G} 2$ genotype $(\mathrm{n}=1)$. They also verified that neutrality indices of the COI were shown negative values in WesternNorthwestern, Northern and Southeastern populations which indicating significant divergence from neutrality and positive but not significant in Central isolates (Spotin et al.).
Eslami et al. (2016), from the Department of Parasitology, Faculty of Veterinary Medicine, University of Tehran, Iran, determined the characteristics of genotype and phenotype of EG derived from wild sheep comparing them with the strains of EG s.s. (sheep-dog) and EG camel strain (camel-dog) in Iran. They verified that the lengths of ITS2 and COI sequences were 378 and $857 \mathrm{bp}$, respectively, for all the sequenced samples. The amplified DNA sequences from both ribosomal and mitochondrial genes were $99 \%$ and 98 $\%$, respectively to that of the ovine strain in the GenBank database. So they conclude that the morpho-molecular features and characteristics of EG in the Iranian wild sheep are the same as those of the sheep-dog EG s.s. Strain (Eslami et al.).

Zait et al. (2016) of the Parasitology and Mycology department, Mustapha University Hospital, Algeria and other related centers, studied 54 isolates from humans admitted in surgical units from Mustapha Hospital and 16 cysts from livestock animals gathered in two geographically distinct slaughterhouses (Tiaret and Tamanrasset). They performed molecular characterization using sequencing of two mitochondrial genes, $\mathrm{COI}$ and NADH dehydrogenase subunit I (NDI). The study confirmed EG G1 as the main genotype (90.7 \%) followed by G3 (7.4 \%) and E. canadensis G6 (1.8 $\%)$. On the other hand, all cysts from sheep, cattle, and goat were identified as EG G1 and the two cysts originating from dromedary as E. canadensis G6. Twenty concatenated haplotypes (COI + NDI) were characterized. Among EG s.s., one haplotype (HL1) was highly predominant in both humans and animals cysts (71.6\%) (Zait et al.).

Sharbatkhori et al. (2016), of the Infectious Diseases Research Center, Golestan University of Medical Sciences, Gorgan, Iran and other related centers, studied 74 hydatid cysts isolated from livestock ( 18 from sheep, 40 from cattle, 9 from camels, 2 from buffaloes and 1 from a goat) and humans (4 isolates) in the Golestan province, northern Iran, southeast of the Caspian sea, using partial sequencing data of COI and NADH dehydrogenase 1 mitochondrial genes. Then, isolates were analysed by PCR amplification and sequencing. The results observed were G1 (78.3 \%), G2 (2.7 \%), G3 (15\%) and G6 (4\%) (Sharbatkhori et al.).

Oudni-Mrad et al. (2016) of the Laboratory of Medical and Molecular Parasitology-Mycology, Faculty of Pharmacy, University of Monastir, Tunisia and other related centers, studied G1 genotype of EG s.s. genetic relationship between lung and hepatic localization in ovine, bovine and human echinococcosis. They used allozyme variation and single strand conformation polymorphism for genetic differentiation and they found that the causes of genetic differentiation were the host species and the localization (lung or liver). Thus it can be assumed that reticulated genetic relationship between liver or 
lung human isolates and isolates from bovine lung, is indicative of recombination or lateral genetic transfer (OudniMrad et al.).

Roinioti et al. (2016) Department of Anatomy and Physiology of Farm Animals, Faculty of Animal Science and Aquaculture, Agricultural University of Athens and other related centers, conducted a genetic analysis of 82 EG isolates from ruminants in Greece. The analysis relied on a PCR assay targeting COI, followed by bidirectional sequence analysis of the amplification product. $97.6 \%$ isolates were allocated to EG s.s. (G1-G3) and were classified in 13 distinct haplotypes ( 9 common and 4 novel) with 12 polymorphic sites. All nucleotide changes proved to be transitions ( $\mathrm{A}^{\prime} \mathrm{G}$ or $\left.\mathrm{C}^{\prime} \mathrm{T}\right)$. Two fertile hydatid cysts of sheep origin of the Peloponnese were identified as E. canadensis (G7 genotype) (Roinioti et al.).
The previously mentioned studies reveal the great variability of genotypes found in the different hosts and different areas of the world.

But only two genotyping experiences in our country (both in La Araucanía), with a limited number of samples (Manterola et al., 2008; Espinoza et al., 2014) is undoubtedly insufficient to have proper information regarding the great variability described in other latitudes, particularly when different techniques for genotype identification have been used.. This is the reason we believe that this proposal will be an important contribution to the knowledge of this disease in our country, from which valuable information can be obtained to advance in the development of preventive measures to reduce the high prevalence rates recorded in both animals and humans (for example, the development of specific vaccines against the most prevalent genotypes

MANTEROLA, C. \& OTZEN, T. Epidemiología molecular de la equinococosis quística: Caracterización genotípica en humanos y diferentes animales. Int. J. Morphol., 34(4):1472-1481, 2016.

RESUMEN: Echinococcus granulosus (EG) es la principal causa de equinococosis quística en humanos y ganado en el mundo. En Chile hay una zoonosis de gran importancia. Las zonas geográficas más afectadas son las Regiones de Aysén, Los Ríos, Los Lagos, Coquimbo y la Araucanía. Por lo tanto, se descubrió que en áreas endémicas de hidatidosis podría haber varias cepas y genotipos de EG. Además, hay pruebas de que algunas cepas y genotipos son más infecciosos para los seres humanos que otros. Este interesante fenómeno de la biología del EG ha sido estudiado utilizando técnicas de biología molecular basadas en la reacción en cadena de la polimerasa (PCR) y análisis de secuencias de ADN, lo que ha permitido caracterizar el complejo de cestode llamado EG sensu lato (sl) EG (G3) y E. canadensis (G6-G10), que presentan una importante variación fenotípica detectable en las características del ciclo biológico, especificidad del huésped intermedio, patrón de desarrollo, patogenicidad, antigenicidad, dinámica de transmisión y, por consiguiente, en las medidas necesarias para el control de la enfermedad. El objetivo de este manuscrito fue describir los diferentes genotipos de EG descritos en humanos y diferentes animales de ganado reportados en la literatura.

PALABRAS CLAVE: Echinococcus granulosus; Genotipos; Citocromo c oxidasa subunidad I; PCR-RAPD.

\section{REFERENCES}

Aaty, H. E.; Abdel-Hameed, D. M.; Alam-Eldin, Y. H.; El-Shennawy, S. F.; Aminou, H. A.; Makled, S. S. \& Darweesh, S. K. Molecular genotyping of Echinococcus granulosus in animal and human isolates from Egypt. Acta Trop.,121(1):125-8, 2012.

Alvarez Rojas, C. A.; Romig, T. \& Lightowlers, M. W. Echinococcus granulosus sensu lato genotypes infecting humans--review of current knowledge. Int. J. Parasitol., 44(1):9-18, 2014.

Alvarez Rojas, C. A.; Ebi, D.; Gauci, C. G.; Scheerlinck, J. P.; Wassermann, M.; Jenkins, D. J.; Lightowlers, M. W. \& Romig, T. Microdiversity of Echinococcus granulosus sensu stricto in Australia. Parasitology, 143(8):1026-33, 2016.

Andresiuk, M. V.; Gordo, F. P.; Saarma, M.; Elissondo, M. C.; Taraborelli, A.; Casalongue, C.; Denegri, G. \& Saarma, U. Echinococcus granulosus genotype G1 dominated in cattle and sheep during 2003-2006 in Buenos Aires province, an endemic area for cystic echinococcosis in Argentina. Acta Trop., 127(2):136-42, 2013.

Babazadeh, M.; Sharifiyazdi, H.; Moazeni, M.; Gorjipour, S. \& Heidari, M. Molecular characterization of a new microvariant of the G3 genotype for Echinococcus granulosus in water buffalo in Iran. Vet. Res. Forum, 6(1):83-7, 2015.
Boufana, B. S.; Campos-Ponce, M.; Naidich, A.; Buishi, I.; Lahmar, S.; Zeyhle, E.; Jenkins, D. J.; Combes, B.; Wen, H.; Xiao, N.; Nakao, M.; Ito, A.; Qiu, J. \& Craig, P. S. Evaluation of three PCR assays for the identification of the sheep strain (genotype 1) of Echinococcus granulosus in canid feces and parasite tissues. Am. J. Trop. Med. Hyg., 78(5):777-83, 2008

Boufana, B.; Umhang, G.; Qiu, J.; Chen, X.; Lahmar, S.; Boué, F.; Jenkins, D. \& Craig, P. Development of three PCR assays for the differentiation between Echinococcus shiquicus, E. granulosus (G1 genotype), and E. multilocularis DNA in the co-endemic region of Qinghai-Tibet plateau, China. Am. J. Trop. Med. Hyg., 88(4):795-802, 2013.

Boufana, B.; Lahmar, S.; Rebaï, W.; Ben Safta, Z.; Jebabli, L.; Ammar, A.; Kachti, M.; Aouadi, S. \& Craig, P. S. Genetic variability and haplotypes of Echinococcus isolates from Tunisia. Trans. R. Soc. Trop. Med. Hyg., 108(11):706-14, 2014.

Boufana, B.; Lett, W. S.; Lahmar, S.; Buishi, I.; Bodell, A. J.; Varcasia, A.; Casulli, A.; Beeching, N. J.; Campbell, F.; Terlizzo, M.; McManus, D. P. \& Craig, P. S. Echinococcus equinus and Echinococcus granulosus sensu stricto from the United Kingdom: genetic diversity and haplotypic variation. Int. J. Parasitol., 45(2-3):161-6, 2015.

Bowles, J.; Blair, D. \& McManus, D. P. Genetic variants within the genus Echinococcus identified by mitochondrial DNA sequencing. Mol. Biochem. Parasitol., 54(2):165-74, 1992. 
Bowles, J. \& McManus, D. P. NADH dehydrogenase 1 gene sequences compared for species and strains of the genus Echinococcus. Int. J. Parasitol., 23(7):969-72, 1993a.

Bowles, J. \& McManus, D. P. Molecular variation in Echinococcus. Acta Trop., 53(3-4):291-305, 1993b.

Bowles, J. \& McManus, D. P. Rapid discrimination of Echinococcus species and strains using a polymerase chain reaction-based RFLP method. Mol. Biochem. Parasitol., 57(2):231-9, 1993c.

Bowles, J.; Blair, D. \& McManus, D. P. Molecular genetic characterization of the cervid strain ('northern form') of Echinococcus granulosus. Parasitology, 109(Pt. 2):215-21, 1994.

Bowles, J.; Blair, D. \& McManus, D. P. A molecular phylogeny of the genus Echinococcus. Parasitology, 110(Pt. 3):317-28, 1995

Casulli, A.; Zeyhle, E.; Brunetti, E.; Pozio, E.; Meroni, V.; Genco, F. \& Filice, C. Molecular evidence of the camel strain (G6 genotype) of Echinococcus granulosus in humans from Turkana, Kenya. Trans. R. Soc. Trop. Med. Hyg., 104(1):29-32, 2010.

Cucher, M. A.; Macchiaroli, N.; Baldi, G.; Camicia, F.; Prada, L.; Maldonado, L.; Avila, H. G.; Fox, A.; Gutiérrez, A.; Negro, P.; López, R.; Jensen, O.; Rosenzvit, M. \& Kamenetzky, L. Cystic echinococcosis in South America: systematic review of species and genotypes of Echinococcus granulosus sensu lato in humans and natural domestic hosts. Trop. Med. Int. Health, 21(2):166-75, 2016.

Cuesta-Bandera, C.; McManus, D. P. \& Rishi, A. K. Characterization of Echinococcus granulosus of Spanish origin by DNA restriction endonuclease analysis and Southern blot hybridization. Int. J. Parasitol., 18(1):137-41, 1988.

Daniel Mwambete, K.; Ponce-Gordo, F. \& Cuesta-Bandera, C. Genetic identification and host range of the Spanish strains of Echinococcus granulosus. Acta Trop., 91(2):87-93, 2004.

Eckert, J. \& Thompson, R. C. Intraspecific variation of Echinococcus granulosus and related species with emphasis on their infectivity to humans. Acta Trop., 64(1-2):19-34, 1997.

Ellsworth, D. L.; Rittenhouse, K. D. \& Honeycutt, R. L. Artifactual variation in randomly amplified polymorphic DNA banding patterns. Biotechniques, 14(2):214-7, 1993.

Eslami, A.; Meshgi, B.; Jalousian, F.; Rahmani, S. \& Salari, M. A. Genotype and Phenotype of Echinococcus granulosus Derived from Wild Sheep (Ovis orientalis) in Iran. Korean J. Parasitol., 54(1):55-60, 2016.

Espinoza, S.; Salas, A. M.; Vargas, A.; Freire, V.; Diaz, E.; Sánchez, G. \& Venegas, J. Detection of the G3 genotype of Echinococcus granulosus from hydatid cysts of Chilean cattle using COX1 and ND1 mitochondrial markers. Parasitol. Res., 113(1):139-47, 2014.

González, L. M.; Daniel-Mwambete, K.; Montero, E.; Rosenzvit, M. C.; McManus, D. P.; Gárate, T. \& Cuesta-Bandera, C. Further molecular discrimination of Spanish strains of Echinococcus granulosus. Exp. Parasitol., 102(1):45-56, 2002.

Guarnera, E. A.; Parra, A.; Kamenetzky, L.; García, G. \& Gutiérrez, A. Cystic echinococcosis in Argentina: evolution of metacestode and clinical expression in various Echinococcus granulosus strains. Acta Trop., 92(2):153-9, 2004.
Konyaev, S. V.; Yanagida, T.; Nakao, M.; Ingovatova, G. M.; Shoykhet, Y. N.; Bondarev, A. Y.; Odnokurtsev, V. A.; Loskutova, K. S.; Lukmanova, G. I.; Dokuchaev, N. E.; Spiridonov, S.; Alshinecky, M. V.; Sivkova, T. N.; Andreyanov, O. N.; Abramov, S. A.; Krivopalov, A. V.; Karpenko, S. V.; Lopatina, N. V.; Dupal, T. A.; Sako, Y. \& Ito, A. Genetic diversity of Echinococcus spp. in Russia. Parasitology, 140(13):1637-47, 2013.

Lavikainen, A.; Lehtinen, M. J.; Meri, T.; Hirvelä-Koski, V. \& Meri, S. Molecular genetic characterization of the Fennoscandian cervid strain, a new genotypic group (G10) of Echinococcus granulosus. Parasitology, 127(Pt. 3):207-15, 2003.

Laurimaa, L.; Davison, J.; Süld, K.; Plumer, L.; Oja, R.; Moks, E.; Keis, M.; Hindrikson, M.; Kinkar, L.; Laurimäe, T.; Abner, J.; Remm, J.; Anijalg, P. \& Saarma, U. First report of highly pathogenic Echinococcus granulosus genotype G1 in dogs in a European urban environment. Parasit. Vectors, 8:182, 2015

Le, T. H.; Pearson, M. S.; Blair, D.; Dai, N.; Zhang, L. H. \& McManus, D. P. Complete mitochondrial genomes confirm the distinctiveness of the horsedog and sheep-dog strains of Echinococcus granulosus. Parasitology, 124(Pt. 1):97-112, 2002.

McManus, D. P. \& Smyth, J. D. Hydatid disease (hidatidosis). Hydatidosis: changing concepts in epidemiology and speciation. Parasitol. Today, 2(6):163-8, 1986

McManus, D. P. \& Rishi, A. K. Genetic heterogeneity within Echinococcus granulosus: isolates from different hosts and geographical areas characterized with DNA probes. Parasitology, 99 Pt. 1:17-29, 1989.

McManus, D. P. \& Bryant, C. Biochemistry, Physiology and Molecular Biology of Echinococcus. In: Thompson, R. C. A. \& Lymbery, A. J. (Eds.). The Biology of Echinococcus and Hydatid Disease. Wallingford, CAB International, 1995. pp.135-81.

Manterola, C. Hidatidosis hepática. Estudio de aspectos clínicos y terapéuticos. Rev. Chil. Cir., 49(4):352-9, 1997.

Manterola, C. \& Otzen, T. Cholangiohydatidosis: An infrequent cause of obstructive jaundice and acute cholangitis. Ann. Hepatol., 2017. In Press.

Manterola, C.; Barroso, M.; Vial, M.; Bustos, L.; Muñoz, S.; Losada, H.; Bello, N.; Hernández, F. \& Carrasco, R. Liver abscess of hydatid origin: clinical features and results of aggressive treatment. A. N. Z. J. Surg., 73(4):220-4, 2003.

Manterola, C.; Vial, M.; Losada, H.; Fonseca, F.; Bustos, L.; Muñoz, S. \& Barroso, M. Uncommon locations of abdominal hydatid disease. Trop. Doct., 33(3):179-80, 2003.

Manterola, C.; Espinoza, R.; Muñoz, S.; Vial, M.; Bustos, L.; Losada, H. \& Barroso, M. Abdominal echinococcosis during pregnancy: clinical aspects and management of a series of cases in Chile. Trop. Doct., 34(3):171-3, 2004.

Manterola, D. C.; Vial, G. M.; Pineda, N. V.; Losada, M. H. \& Barroso, V. M. Factores asociados a morbilidad en cirugía de la hidatidosis hepática. Rev. Chil. Cir., 56(2):154-9, 2004.

Manterola, C.; Benavente, F.; Melo, A.; Vial, M. \& Roa, J. C. Description of Echinococcus granulosus genotypes in human hydatidosis in a region of southern Chile. Parasitol. Int., 57(3):342-6, 2008.

Micheli, M. R.; Bova, R.; Pascale, E. \& D’Ambrosio, E. Reproducible DNA fingerprinting with the random amplified polymorphic DNA (RAPD) method. Nucleic Acids Res., 22(10):1921-2, 1994. 
Mrad, S.; Filisetti, D.; Oudni, M.; Mekki, M.; Belguith, M.; Nouri, A.; Sayadi, T.; Lahmar, S.; Candolfi, E.; Azaiez, R.; Mezhoud, H. \& Babba, H. Molecular evidence of ovine (G1) and camel (G6) strains of Echinococcus granulosus in Tunisia and putative role of cattle in human contamination. Vet. Parasitol., 129(3-4):267-72, 2005.

Nakao, M.; Li, T.; Han, X.; Ma, X.; Xiao, N.; Qiu, J.; Wang, H.; Yanagida, T.; Mamuti, W.; Wen, H.; Moro, P. L.; Giraudoux, P.; Craig, P. S. \& Ito, A. Genetic polymorphisms of Echinococcus tapeworms in China as determined by mitochondrial and nuclear DNA sequences. Int. J. Parasitol., 40(3):379-85, 2010.

Oudni-Mrad, M.; Cabaret, J.; M'rad, S.; Chaâbane-Banaoues, R.; Mekki, M.; Zmantar, S.; Nouri, A.; Mezhoud, H. \& Babba, H. Genetic relationship between the Echinococcus granulosus sensu stricto cysts located in lung and liver of hosts. Infect. Genet. Evol., 44:356-60, 2016.

Olivier, M.; Meehl, M. A. \& Lust, G. Random amplified polymorphic DNA (RAPD) sequences as markers for canine genetic studies. J. Hered., 90(1):78-82, 1999.

Ponce-Gordo, F. \& Cuesta-Bandera, C. Differentiation of Spanish strains of Echinococcus granulosus using larval rostellar hook morphometry. Int. J. Parasitol., 27(1):41-9, 1997a.

Ponce-Gordo, F. \& Cuesta-Bandera, C. Echinococcus granulosus: characterization of the Spanish strains using in vitro vesicular development. J. Helminthol., 71(1):61-7, 1997b.

Ponce-Gordo, F. \& Cuesta Bandera, C. Observations on the Echinococcus granulosus horse strain in Spain. Vet. Parasitol., 76(1-2):65-70, 1998.

Roelfsema, J. H.; Nozari, N.; Pinelli, E. \& Kortbeek, L. M. Novel PCRs for differential diagnosis of cestodes. Exp. Parasitol., 161:20-6, 2016.

Roinioti, E.; Papathanassopoulou, A.; Theodoropoulou, I.; Simsek, S. \& Theodoropoulos, G. Molecular identification of Echinococcus granulosus isolates from ruminants in Greece. Vet. Parasitol., 226:138-44, 2016.

Santivañez, S. J.; Gutierrez, A. M.; Rosenzvit, M. C.; Muzulin, P. M.; Rodriguez, M. L.; Vasquez, J. C.; Rodriguez, S.; Gonzalez, A. E.; Gilman, R. H.; Garcia, H. H. \& Cysticercosis Working Group in Peru. Human hydatid disease in Peru is basically restricted to Echinococcus granulosus genotype G1. Am. J. Trop. Med. Hyg., 79(1):89-92, 2008.

Scott, J. C. \& McManus, D. P. The random amplification of polymorphic DNA can discriminate species and strains of Echinococcus. Trop. Med. Parasitol., 45(1):1-4, 1994.

Scott, J. C.; Stefaniak, J.; Pawlowski, Z. S. \& McManus, D. P. Molecular genetic analysis of human cystic hydatid cases from Poland: identification of a new genotypic group (G9) of Echinococcus granulosus. Parasitology, 114(Pt. 1):37-43, 1997.

Serra, I.; Araya, C.; Araneda, J. \& Serra, V. Situación actual de la hidatidosis humana en Chile. Dos proposiciones de corrección de su subnotificación. Rev. Med. Chil., 123:659-69, 1995.

Sharbatkhori, M.; Tanzifi, A.; Rostami, S.; Rostami, M. \& Fasihi Harandi, M. Echinococcus granulosus sensu lato genotypes in domestic livestock and humans in Golestan province, Iran. Rev. Inst. Med. Trop. Sao Paulo, $58: 38,2016$

Siles-Lucas, M.; Cuesta-Bandera, C. \& César-Benito, M. Random amplified polymorphic DNA technique for speciation studies of Echinococcus granulosus. Parasitol. Res., 79(4):343-5, 1993.
Siles-Lucas, M.; Felleisen, R.; Cuesta-Bandera, C.; Gottstein, B. \& Eckert, J. Comparative genetic analysis of Swiss and Spanish isolates of Echinococcus granulosus by southern hybridization and Random Amplified Polymorphic DNA technique. Appl. Parasitol., 35(2):107-17, 1994.

Siles-Lucas, M.; Benito, M. C. \& Cuesta-Bandera, C. Echinococcus granulosus: genomic and isoenzymatic study of Spanish strains isolated from different intermediate hosts. Vet. Parasitol., 63(3-4):273-82, 1996.

Snábel, V.; D’Amelio, S.; Mathiopoulos, K.; Turceková, L. \& Dubinskł, P. Molecular evidence for the presence of a G7 genotype of Echinococcus granulosus in Slovakia. J. Helminthol., 74(2):177-81, 2000.

Soriano, S. V.; Pierangeli, N. B.; Pianciola, L.; Mazzeo, M.; Lazzarini, L. E.; Saiz, M. S.; Kossman, A. V.; Bergagna, H. F.; Chartier, K. \& Basualdo, J. A. Molecular characterization of Echinococcus isolates indicates goats as reservoir for Echinococcus canadensis G6 genotype in Neuquén, Patagonia Argentina. Parasitol. Int., 59(4):626-8, 2010.

Spotin, A.; Mahami-Oskouei, M.; Harandi, M. F.; Baratchian, M.; Bordbar, A.; Ahmadpour, E. \& Ebrahimi, S. Genetic variability of Echinococcus granulosus complex in various geographical populations of Iran inferred by mitochondrial DNA sequences. Acta Trop., pii:S0001-706X(16)300924, 2016.

Thompson, R. C. \& Lymbery, A. J. The nature, extent and significance of variation within the genus Echinococcus. Adv. Parasitol., 27:209-58, 1988.

Thompson, R. C.; Lymbery, A. J. \& Constantine, C. C. Variation in Echinococcus: towards a taxonomic revision of the genus. Adv. Parasitol., 35:145-76, 1995

Thompson, R. C. Presidential address: rediscovering parasites using molecular tools--towards revising the taxonomy of Echinococcus, Giardia and Cryptosporidium. Int. J. Parasitol., 32(5):493-6, 2002.

Valentini, A.; Timperio, A. M.; Cappuccio, I. \& Zolla, L. Random amplified polymorphic DNA (RAPD) interpretation requires a sensitive method for the detection of amplified DNA. Electrophoresis, 17(10):1553-4, 1996.

Venegas, J.; Espinoza, S. \& Sánchez, G. Estimation of costs caused by cystic echinococcosis. Rev. Med. Chil., 142(8):1023-33, 2014.

Zait, H.; Kouidri, M.; Grenouillet, F. E.; Umhang, G.; Millon, L.; Hamrioui, B. \& Grenouillet, F. Molecular characterization of Echinococcus granulosus sensu stricto and Echinococcus canadensis in humans and livestock from Algeria. Parasitol. Res., 115(6):2423-31, 2016.

Zhang, L.; Eslami, A.; Hosseini, S. H. \& McManus, D. P. Indication of the presence of two distinct strains of Echinococcus granulosus in Iran by mitochondrial DNA markers. Am. J. Trop. Med. Hyg., 59(1):171-4, 1998a.

Zhang, L. H.; Chai, J. J.; Jiao, W.; Osman, Y. \& McManus, D. P. Mitochondrial genomic markers confirm the presence of the camel strain (G6 genotype) of Echinococcus granulosus in north-western China. Parasitology, 116(Pt. 1):29-33, 1998b.

Correspondence to:

Prof. Dr. Carlos Manterola,

Department of Surgery and CEMyQ Universidad de La Frontera

Temuco - CHILE

Received: 02-06-2016 Accepted: 18-08-2016

E-mail: carlos.manterola@ufrontera.cl 